\title{
Apresentação - Teoria e história da historiografia: do giro linguístico ao giro ético-político*
}

\author{
Introduction - Theory and History of Historiography: from the Linguistic \\ Turn to the Ethical-Political Turn
}

\author{
Marcelo de Mello Rangel \\ mmellorangel@yahoo.com.br \\ Professor Adjunto \\ Universidade Federal de Ouro Preto \\ Rua do Seminário, s/n - Centro \\ 35420-000 - Mariana - MG \\ Brasil

\section{Valdei Lopes de Araujo} \\ valdei354@gmail.com \\ Professor Adjunto \\ Universidade Federal de Ouro Preto \\ Rua do Seminário, s/n - Centro \\ 35420-000 - Mariana - MG \\ Brasil
}

\section{8}

* Este texto é resultado parcial de projetos de pesquisa financiados pelo Conselho Nacional de Desenvolvimento Científico e Tecnológico (CNPq) e pela Fundação de Amparo à Pesquisa do estado de Minas Gerais (Fapemig); no caso desta última, pelo programa de apoio a grupos emergentes que financia o projeto coletivo de pesquisa "Variedades do Discurso Histórico" no âmbito do Núcleo de Estudos em História da Historiografia e Modernidade (NEHM). 
Este dossiê reúne conferências apresentadas no $6^{\circ}$ Seminário Brasileiro de História da Historiografia (SNHH), o qual foi realizado no ano de 2012 na cidade de Mariana, e, nele, todos os autores tematizam o problema do giro linguístico. Trata-se das conferências de Guilhermo Zermeño Padilla (Colegio de México), Rogério Forastieri da Silva (Colégio Etapa - SP), Temístocles Cezar (Universidade Federal do Rio Grande do Sul - UFRGS) e Sérgio Campos Matos (Universidade de Lisboa). A escolha do tema se deveu, sobretudo, aos 40 anos da publicação do livro de Hayden White Meta-História: a Imaginação Histórica do Século XIX, que se completariam no ano seguinte ao $6^{\circ} \mathrm{SNHH}$, em 2013.

As discussões que tivemos ao longo do evento e os textos que estamos publicando problematizam o giro linguístico e nos auxiliam a refletir sobre ele, ou, ainda, sobre o questionamento da relação entre realidade, pensamento e linguagem, e isso especialmente no interior da historiografia. Ainda a partir de nossas discussões no Seminário e, especialmente, dos textos que compõem o dossiê, podemos abordar os séculos XVIII e XIX como a origem, quer da compreensão que o giro linguístico problematizou - a de que o pensamento pode produzir enunciados privilegiados em relação à realidade -, quer de elementos fundamentais à própria estruturação de sua crítica.

É preciso ressaltar, ainda, que o conceito mais tradicional de giro linguístico o situa como um fenômeno recente, cuja origem pode ser datada das décadas do período pós-segunda Grande Guerra. Aqui, preferimos pensar o giro linguístico como um deslocamento histórico-estrutural mais amplo que pode ser definido em torno da clássica descrição foucaultiana da crise da representação, ou seja, do divórcio progressivo entre as palavras e as coisas que tem no século XVIII seu momento decisivo (FOUCAULT 1999). De modo algum, no entanto, essa definição mais ampla recusa a existência e relevância de abordagens que tratam o fenômeno como um evento/processo decisivo à história intelectual recente.

Interessa-nos, assim, pensar as condições de possibilidade do giro linguístico constituídas alguns séculos antes, a saber, a ampla percepção da "aceleração crescente das transformações no tempo", própria da modernidade e que tornou possível o questionamento acerca das funções tradicionais da "historiografia"; e, num segundo momento, a própria colocação radical do problema epistemológico da "parcialidade" e do ponto de vista. De modo complementar, podemos explicitar e compreender, em seguida, duas tradições específicas no interior do giro linguístico, buscando, por fim, refletir sobre possíveis repercussões provocadas por esse deslocamento epistemológico.

\section{A centralidade do problema da linguagem nas origens da modernidade}

Sobre as condições de possibilidade para a realização do giro linguístico, temos, em primeiro lugar, a constituição de uma experiência do tempo específica, profundamente acelerada, para usar um termo caro a Reinhart Koselleck, ou, ainda, trata-se da perda do caráter de imediatidade dos significados e sentidos capazes de orientar os homens e de promover a estabilidade da autorreferência humana (KOSELLECK 2006). Dessa forma, conceitos mais tradicionais e mais recentes como os de Deus, Estado, Absolutismo, Parlamento, Constituição, 
História, Natureza, Ciência, Império, Nação, Comércio, Anarquia, República, Liberalismo, Comunismo, Capitalismo ou Socialismo passam a disputare a requerer uma possível posição de hegemonia. Também, um conjunto de acontecimentos e processos históricos como a Revolução Industrial, a Independência dos Estados Unidos, a Revolução Francesa e a Expansão Napoleônica, bem como a Independência das colônias espanholas e portuguesas na América, entre outros, foram experimentados e produzidos como realidades inéditas para as quais não se tinha respostas suficientes no repertório tradicional (ARAUJO 2008; 2009; 2011; RANGEL 2014; LYNCH 2014).

Os sentidos disponíveis foram contestados e se viram na necessidade de disputar espaço com outros que iam aparecendo ao longo e na medida em que a modernidade ganhava forma. Paradoxalmente, esse processo de disputa, que tinha o objetivo de restituir uma ordem maximamente estável, acabou estimulando a crítica e as oposições de modo a intensificar a referida aceleração. Por fim, ia ocorrendo a diferenciação radical das conjunturas históricas, e, a um só tempo, ia sendo produzida a identidade moderna, na dependência, é claro, de metanarrativas que assegurassem a totalização presente e futura do que supostamente era deixado para trás (GUMBRECHT 1998).

Esse movimento acelerado da "História" foi responsável pela constituição de um aspecto específico no que tange à atualização da condição de sua temporalização - a atualização da tensão entre "espaço de experiência" e "horizonte de expectativa" -, que resultou no encurtamento significativo do

320 "espaço de experiência". Isso significa que mediante conjunturas maximamente inéditas os homens iam se comportando de forma variada e dinâmica de modo a intensificar e produzir realidades que iam se diferenciando significativamente. O resultado dessa experiência temporal profundamente acelerada foi que os homens perderam boa parte da confiança em seus passados, em seu poder de rearticulação, de reorganização do presente.

Neste momento, temos a primeira condição de possibilidade para o giro linguístico: a contestação radical da história magistra vitae; consequentemente, aparece a possibilidade de colocação da questão: "para que serve a história ("historiografia")?" Ela tornará possível, por sua vez, o aparecimento das filosofias da história e, em seguida, dos historicismos. Aliás, é importante ressaltar que utilizamos a expressão "história magistra vitae" como uma metonímia de uma forma própria de experimentar os eventos históricos que amadureceu ao longo de séculos da história ocidental, que passou por diferentes formatos e modelos, mas que apontava sempre para elementos relativamente estáveis no plano experiencial.

Filósofos da história e historicistas se organizaram no sentido de responder a essa pergunta pelas condições de possibilidade do conhecimento histórico e de sua relevância para os homens. Os primeiros preconizam que a "História" se realiza necessariamente a partir de determinados sentidos, a despeito do homem e concretizando sua perfectibilidade; trata-se da lógica do progresso. A "historiografia" passa a constituir-se a partir da responsabilidade de evidenciar os sentidos fundamentais próprios da "História" com o objetivo de acelerar sua realização e de reduzir, assim, o sofrimento dos homens em busca da felicidade. 
Dessa forma, temos a possibilidade de superação do problema colocado à "historiografia" pela aceleração radical do tempo, pois, se, por um lado, temos um processo de diferenciação significativa e incessante da "História" - e, logo, das conjunturas que vão se sucedendo -, temos, por outro lado, a possibilidade de direcionar um olhar mais profundo à "História", de perceber e explicitar os seus sentidos intrínsecos, estes sim inalteráveis e teleológicos.

No entanto, na medida mesmo em que os filósofos da história iam liberando esses sentidos, a "História", mais propriamente, não ia permitindo que eles comprovassem sua excepcionalidade - no interior daquele ritmo acelerado, tais sentidos iam sendo contestados de maneira que não reuniram força suficiente para determinar a realidade e comprovar sua constituição privilegiada. O resultado imediato foi a contestação das filosofias da história, especialmente pelos historicistas, menos em razão de sua compreensão de fundo acerca da temporalização da "História" do que em razão dos procedimentos necessários à observação e explicitação desse(s) sentido(s). Trata-se de uma espécie de momento metodológico profundamente teórico, dedicado à discussão e produção das condições de possibilidade ideias à observação e evidenciação das determinações próprias da "História", aquelas que, uma vez disponibilizadas e intensificadas, seriam capazes de acelerar a realização do processo histórico, evitando sofrimentos. O problema é que a modernidade também não permitiu que os enunciados historicistas a reestabilizassem, ao menos num primeiro momento e da forma pretendida, de modo que eles também passaram a ser contestados.

Temos, então, o aparecimento da segunda condição de possibilidade à constituição do giro linguístico, esta mais propriamente epistemológica. Da aceleração radical do tempo própria da modernidade surge o questionamento da história representada e, ainda, a possibilidade de se perguntar radicalmente pela sua função, procedimento que será reeditado com vigor no interior do giro linguístico e, mais, que será fundamental para o aparecimento das filosofias da história e dos historicismos, os quais, por sua vez, acabaram por tornar possível (por liberar) o questionamento significativo de toda e qualquer relação privilegiada entre linguagem e realidade, problema prioritário no interior das tradições que confluem no giro linguístico. A partir das filosofias da história, temos uma primeira resposta que não fora absorvida pela "História", o que orientou os historicistas a desenvolver suas reflexões e metodologias. O que estava em questão para os historicistas era que o problema dos filósofos da história não era o seu diagnóstico da "História", mas sim a forma ou o caminho proposto, profundamente arbitrário, "subjetivo". Eles não teriam sido capazes de tematizar com a atenção e o cuidado adequados a posição de base própria dos homens em geral, inclusive dos homens de ciência - seu posicionamento no interior de um mundo transcendental, e, portanto, determinante. Em outras palavras, os historicistas evidenciaram (e liberaram) um problema radical: a relação de intimidade entre os enunciados, inclusive os historiográficos, e os mundos a partir dos quais eles se tornam possíveis. Para tanto, haveria a possibilidade de constituição de um conjunto de métodos e protocolos capazes de abrir um acesso controlado à realidade histórica, garantindo, assim, a possibilidade de 
explicitar os sentidos próprios da realização necessária da "História" como realidade-processo de modo a garantir à humanidade as condições propícias para o seu progresso e para a redução do sofrimento.

No entanto, como os sentidos liberados pelos historicistas também não foram capazes de se mostrar fundamentais para a "História" (e isso porque não ocuparam, ao menos num primeiro momento, a condição de imediatidade), surgiram os seguintes problemas: (1) ou bem a realidade histórica não possui sentido(s), (2) ou bem possui, mas nem mesmo os métodos e protocolos mais sofisticados seriam capazes de oferecer as condições de possibilidade ideais para que os historiadores pudessem evidenciá-lo(s). Trata-se, ao fim, da crise do "observador de segunda ordem" (GUMBRECHT 1998; 1999).

Desse modo, os próprios historicismos liberam, inclusive em razão de sua força teórica e sensibilidade sofisticada, a segunda condição de possibilidade que mencionamos mais acima, fundamental para a constituição do giro linguístico, a saber, o problema epistemológico da impossibilidade de produção de qualquer enunciado exclusivo sobre a realidade, movimento que, por sua vez, intensificou o questionamento acerca da função (ou da necessidade) da história ao longo do século XX. Assim, a modernidade e suas filosofias da história e historicismos constituem duas condições possíveis para o giro linguístico: (1) a aceleração do tempo, que desestabiliza a imediatidade quase tangível das histórias acumuladas pela história magistra vitae e, por conseguinte, torna possível a pergunta "para que serve a história?" e (2) o próprio questionamento

322 acerca de toda e qualquer possibilidade de constituição de critérios de seleção de enunciados privilegiados em relação à realidade, inclusive (e em nosso caso especialmente) no interior da historiografia.

Temos, então, duas condições importantes para a constituição do giro linguístico: uma histórico-estrutural - a aceleração radical do tempo própria da modernidade e o consequente questionamento acerca da serventia da história - e, posteriormente, a segunda, histórico-epistemológica - a tematização do que podemos chamar de impossibilidade de qualquer acesso privilegiado em relação à realidade. Desse modo, o século XX herda essa espécie de desafio epistemológico disponibilizado ao longo do século XIX, o qual foi enfrentado por pelo menos duas tradições distintas, a fenomenológico-hermenêutica e a neo-historicista (ou pós-moderna). Em outras palavras, podemos dizer que o giro linguístico se constitui (e intensifica) a partir dessas duas tradições.

\section{Duas tradições entre convergência e dispersão}

A tradição fenomenológico-hermenêutica está mais precisamente associada a Husserl e a Heidegger e, após eles, a filósofos, historiadores e teóricos da literatura como Gadamer, Paul Ricoeur, Koselleck e Gumbrecht, além de ter sido importante para filósofos e historiadores como Walter Benjamin, Jörn Rüsen e François Hartog. A despeito das profundas diferenças entre eles, o que está em questão nesta tradição é que todo e qualquer pensamento e ação no interior do presente é determinado pela relação de intimidade com passados e futuros, os quais se constituem como ponto de determinação transcendental que orienta 
e determina cada presente. Em função disso, ao fim, há a intensificação da premissa fundamental do giro linguístico, a de que não há a possibilidade de construção de enunciados privilegiados em relação à realidade, ou mesmo objetivos no sentido de a realidade estar disponível exatamente à frente de quem os produz, e isto de acordo com o termo alemão Gegenständlichkeit.

A tradição neo-historicista ou pós-moderna está mais precisamente vinculada a filósofos, historiadores e teóricos da literatura como Wittgenstein, Roland Barthes, Lyotard, Jean Baudrillard, Hayden White, Frank Ankersmit, Keith Jenkins, Stephen Greenblatt, entre outros, e sua compreensão de base é a de que há uma autonomia radical do presente em relação ao passado e, mais, que são os homens no interior do presente que reconstituem certa reorganização apenas provisória da "História". ${ }^{1}$ Em outras palavras, sua percepção acerca do tempo é a de que ele é "deveniente", que se diferencia radical e incessantemente, intensificando, nesse sentido, a compreensão de tempo própria do "cronótopo historicista", para usar um termo caro a Gumbrecht; por esta razão, inclusive, é que eles são chamados de neo-historicistas (GUMBRECHT 1999; 1998; ARAUJO 2006a; RANGEL 2010; RANGEL; RODRIGUES 2012). Assim, no interior dessa percepção temporal, o pensamento histórico é compreendido como sendo o âmbito (ou estratégia) ideal para a constituição de enunciados ideais para a estabilização temporal (ainda que provisória). Ao fim, a despeito das distinções em relação à tradição fenomenológico-hermenêutica, é intensificada aquela determinação fundamental do giro linguístico, a de que não existem enunciados privilegiados (objetivos, no sentido que sublinhamos acima) em relação à realidade.

Para sermos ainda mais precisos no que tange à primeira tradição, a fenomenológico-hermenêutica, podemos falar da seguinte estrutura temporal de base: o homem é a estrutura própria da constituição e temporalização da "História". É a partir dele que ela se sedimenta e se diferencia, e isso por uma tensão entre determinado passado protagonista e que vige no presente, outros passados obscurecidos mas que continuam disputando espaços de protagonismo no interior da "História" (do presente) e, por último, a sua própria recepção (ou falta de recepção) no presente. Segundo Heidegger, por exemplo, o homem é uma estrutura específica, o Dasein, a qual é determinada pelo seu "aí" e pelo "poder-ser" que ele também é. O aí, ou, ainda, o "mundo", significa, mais propriamente, um conjunto de significados e de sentidos sedimentados a partir dos quais o Dasein se orienta, e o poder-ser é a própria necessidade de projetar ou mesmo de desejar algo mais do que determinado mundo oferece ao menos de forma evidente. Dessa forma, é a partir da tensão entre aí e poder-ser que a "História" ou mesmo o tempo se temporaliza ou, ainda, diferencia-se e sedimenta-se (HEIDEGGER 2008, §§ 72-77; ARAUJO 2013; CASANOVA 2013).²

\footnotetext{
${ }^{1}$ Em relação a este esquema que aponta para a existência de duas grandes tradições no interior do giro linguístico, bem como associa determinados autores a um ou a outro grupo, trata-se de uma organização didática, de modo que reconhecemos as diferenças no interior de cada uma destas tradições, e mais, a própria possibilidade de questionamento da relação autor-tradição que anotamos ou mesmo o rearranjo da lista apresentada.

${ }^{2}$ Ainda sobre este movimento de temporalização do tempo ou da "História" a partir do Dasein, ver a discussão sobre morte e nascimento no quinto capítulo da segunda sessão de Ser e Tempo.
} 
É fácil perceber a insuficiência da definição disciplinar especializada para dar conta do que Heidegger chama de histórico. Daí sua distinção entre o historiográfico, um tipo de abordagem dos fenômenos do mundo da vida que partisse do pressuposto da centralidade da temporalidade (Dasein) como estrutura fundamental do humano, e o historiológico, o que conhecemos como ciência histórica no sentido mais tradicional. Essa consciência pode ajudar-nos a descongelar as representações históricas a partir da investigação da oscilação entre a historicidade própria e a imprópria, o que daria lugar ao acolhimento e evidenciação de determinados passados mais ou menos obscurecidos no interior do presente, tornando possível a reorganização da tríade - passado, presente e futuro - a partir da historiografia. Esses dois adjetivos ("própria" e "imprópria") não apontam para valores desiguais em Heidegger, mas para duas formas existenciais (na origem, complementares) de se relacionar com o tempo histórico. A imprópria é determinada pela necessidade humana de abordar o mundo circundante reduzindo-o a objetos de uso, ao alcance das mãos, e isso a partir de um sentido ou de um conjunto de sentidos específico; por isso, tende a objetivar também o passado e o futuro, que deixam de ser experimentados como um ambiente. Em suma, o que há no modo impróprio é a repetição incessante de um sentido protagonista que torna improvável o movimento de diferenciação da "História" ou, ainda, seu descongelamento. Assim, recuperar a dimensão ecológica do tempo histórico, que para Heidegger é sua dimensão primária, pode revelar a historicidade própria. Aqui, as dimensões passado, presente e 324 futuro são intercambiáveis e modalizáveis, valorizando-se a simultaneidade em lugar da sucessão.

O que temos até hoje chamado de historiografia é a redução da investigação e de sua consciência à dimensão imprópria da historicidade. Desse modo, a história da historiografia $(\mathrm{HH})$ deixaria de ser uma espécie de auxiliar da história ciência para tornar-se uma abordagem global do humano com particular atenção às estruturas existenciais da temporalidade. Além do ganho cognitivo, poderíamos fazer justiça à enorme expansão dos objetos e fenômenos que a comunidade tem investigado. Assim, abordagens tradicionais, especializadas, como a história intelectual, poderiam ser traduzidas nesse novo universo. Esse deslocamento parte da aceitação de que toda historiografia, como historiologia, também produzirá sempre algum congelamento funcional de nossa experiência; esta é sua principal função: fabricar, por redução, objetos identitários e orientações práticas para a realização de nossa necessidade de operar sobre o mundo e os outros. Mas esse aspecto historiológico, que culmina com a ciência histórica e resulta na formação de tecnologias de identidade, orientação, entretenimento histórico etc, não esgota toda a nossa necessidade de história, nem explica a totalidade dos fenômenos de representação e apresentação históricos (ARAUJO 2012).

Mesmo no discurso histórico orientado pelos padrões da ciência, percebemos, em todo momento, elementos contrabandeados de outras formas de experiência que não a pragmático-científica. Ao tornar esse discurso seu objeto de análise, a HH ampliou nossa capacidade de identificar alguns desses "contrabandos", mas chegou a um impasse em relação aos efeitos dessas descobertas no 
projeto historiológico, ou seja, da ciência e tecnologias históricas. De um lado, temos aqueles que ainda esperam dela uma purificação e a liberação das forças que travam o progresso do discurso científico e, de outro, os que, adotando uma crítica radical a esse discurso, afirmam o que seria aparentemente o seu oposto, a subjetividade como fidúcia de uma democracia cognitiva que levaria à equivalência de todas as representações. Claro que esses dois caminhos são dois lados complementares da historiologia, sem a capacidade de avançar para além da dimensão imprópria da historicidade. Essa estrutura que acabamos de explicitar a partir de Heidegger também é fundamental para as reflexões de Benjamin e de Koselleck sobre a "História". Benjamin explicita que (1) determinado passado protagonista determina a constituição do presente e que (2) determinados passados maximamente obscurecidos se remetem a certos presentes, em momentos de "perigo", constituindo as condições de possibilidade ideias para a diferenciação do tempo ou da "História" (no Jetztzeit, "tempo de agora"), o que, por conseguinte, abre novas possibilidades de projetos, esperanças e desejos, ou, ainda, de futuros possíveis (BENJAMIN 2005; RANGEL 2011; 2013).

No caso de Koselleck, a estrutura que descreve o movimento de constituição, sedimentação e diferenciação da "História" é semelhante; trata-se da tensão antropológica entre "espaço de experiência" e "horizonte de expectativa", a qual, aliás, também é fundamental para compreendermos parte dos trabalhos de Rüsen, que pensa a partir das categorias "experiência" e "intenção", e de Hartog, com seu "regime de historicidade" (KOSELLECK 2006; RÜSEN 2001; HARTOG 2003). Para Koselleck, o "espaço de experiência", ou, ainda, um conjunto específico de significados e de sentidos disponibilizados por determinados passados, e o "horizonte de expectativa", tendência a projeções, esperanças e desejos, tensionam-se no presente, e isso a partir de experiências do tempo e acontecimentos históricos específicos, provocando diferenciações e sedimentações da "História".

Essa estrutura também é fundamental para o pensamento de Hans Ulrich Gumbrecht, e isso a partir da categoria "fascinação" (GUMBRECHT 1999; 2011). Trata-se da necessidade/possibilidade antropológica de projeção, expectativa ou ainda desejo, estrutura fundamental, inclusive, para o que o autor chama de necessidade dos homens em geral em relação ao material produzido pela historiografia e pelos demais âmbitos da cultura histórica. E, mais, é a própria relação entre essa determinação antropológica, a fascinação (desejo de transcender o nascimento também em direção a mundos passados), e determinada conjuntura contemporânea marcada pelo encurtamento significativo do futuro ou do "horizonte de expectativa" que explicaria ou ajudaria a diagnosticar o "cronótopo" no interior do qual nos encontramos, o broad present ou "presente alargado".

Berber Bevernage, por sua vez, identifica a passagem acelerada do modelo da amnésia para o da memória da violência e do direito à verdade como um dos efeitos dessas transformações mais amplas no regime de historicidade modernista (ou historicista). Em sua avaliação, a crise da consciência moderna do tempo e de sua política de sincronização tornaria menos eficazes as práticas 
modernistas de afastar o passado do presente, sendo, então, o presente vivido como um espaço ocupado por um excesso de memórias traumáticas (HARTOG 2003). Em um contexto de excesso de memória, a política da amnésia torna-se impraticável. Para o discurso modernista, a destruição deliberada de um passado morto poderia ser vista como a aceleração dos efeitos normais de um tempo progressista; com a crise desse otimismo, no entanto, torna-se cada vez mais difícil esquecer. ${ }^{3}$

A presença dessas memórias anacrônicas, do ponto de vista do discurso modernista, torna cada vez mais problemática a tarefa do discurso histórico de traçar uma clara linha separando presente e passado. Citando Primo Levi, Bevernage escreve que as "memórias das ofensas têm continuamente crescido desde o Holocausto e agora desafiam profundamente a consciência moderna do tempo" (BEVERNAGE 2012, p. 465-466). Teríamos, então, uma espécie de colisão entre a tentativa do discurso modernista de organizar linearmente 0 tempo, atribuindo ao presente a centralidade única da presença, e o discurso da memória, que insiste na permanência e na simultaneidade.

Incapaz de traçar uma clara distinção entre presente e passado, as comissões da verdade em sociedades pós-traumáticas voltar-se-iam para a história "[...] in order to pacify the troublesome force of 'memory.' History, then, is introduced in the field of transitional justice not despite an already overabundant memory but because of it" (BEVERNAGE 2012, p. 493). O problema das comissões deixa de ser apenas o do estabelecimento de uma consciência histórica por meio do 326 tratamento da memória: elas tornam-se o palco no qual duas formas distintas de memória se confrontam, a do passado irreversível (historiografia no sentido tradicional) e a do passado irrevogável, o das vítimas. Para as vítimas, o passado não passou e não passará, cabendo aos vivos assumir a responsabilidade por essa copresença.

Para Bevernage, ainda, a historiografia modernista estaria assentada na ideia de irreversibilidade do passado; sua função seria distanciar o passado, livrar as sociedades daquilo que Hayden White, em seu famoso artigo, chamou de "fardo da história" (BEVERNAGE 2012). Desse modo, podemos entender o sucesso da fórmula construtivista de que o passado somente existiria na medida em que fosse (re)inventado pelo historiador, provendo o tempo presente do privilégio exclusivo da presença "real". Embora não enfrente esse problema diretamente, Bevernage nos ajuda a pensar ao identificar como na historiografia modernista os conceitos metafísicos de subjetividade e de memória se tornaram centrais. Nesse mundo em que tudo é construído, inclusive a nação, restaria "apenas" a crença na realidade dos sujeitos.

Assim, compreendemos melhor a temporalidade neo-historicista, a concepção de que a "História" se diferencia incessantemente e cabe ao presente, autônomo (quase independente), constituir as interpretações possíveis capazes, por conseguinte, de reconstituir sentidos e orientações provisórias, quer de

\footnotetext{
3 "The problem with the past and the reason that it continues to torment, according to Ignatieff, is precisely that it is not past: 'Crimes can never be safely fixed in the historical past: they remain locked in the eternal present crying out for vengeance" (BEVERNAGE 2012, p. 441).
} 
forma mais subjetiva, quer de forma mais socialmente orientada. Desse modo, Hayden White, por exemplo, assinala que há acontecimentos maximamente desestabilizadores, capazes de provocar uma desarticulação radical do presente, o que, por conseguinte, faria com que os sentidos e sugestões disponibilizados pelos passados se tornassem inadequados. Ao tematizar o problema do Holocausto e da "solução final", o autor afirma que os homens do século XX (e ainda do XXI) precisariam reconstituir conjuntos de significados e de sentidos adequados à existência no interior de um mundo que teria colocado em questão (quase) toda a moralidade e as orientações próprias da história ocidental. E ainda no que toca à possibilidade de constituição de enunciados que tematizassem aquele momento, seria necessário insistir numa espécie de "livre jogo" entre memória e imaginação, e isso para que determinadas lembranças fossem, aos poucos, enfrentadas e explicitadas, o que teria o poder de (1) reorganizar a linguagem e a moralidade e (2) produzir conhecimento (apenas) indicativo e, por conseguinte, orientador. Nesse sentido, temos um conjunto de proposições específicas de Hayden White no que tange ao método adequado ao enfrentamento gnosiológico de momentos radicalmente críticos. Apesar de não termos, aqui, espaço para explicitar esse método com o cuidado devido, já temos material suficiente para inserir o pensamento do autor norte-americano no interior do giro linguístico, e isso precisamente no que se refere à compreensão fundamental que reúne os historiadores neo-historicistas, a saber, a de que o presente é autônomo (quase independente) em relação ao passado e precisa se dedicar à reconstituição da "História", que, por sua vez, é determinada pela necessidade incessante e por vezes radicalmente crítica de diferenciação (WHITE 2003).

Frank Ankersmit também compreende que não há possibilidade de relação privilegiada entre pensamento e realidade ou entre os enunciados historiográficos e o passado, e isso justo em razão da diferenciação radical entre passado e presente; por isso, o presente acaba sendo um âmbito decisivo de ressignificação e de reorganização do passado (ANKERSMIT 2001; 2012; ARAUJO 2006b). Segundo o autor, se, alguma vez, já foi possível alguma relação privilegiada entre presente e passado (e esta argumentação tem um tom irônico), isso deixou de ser possível no momento em que houve uma multiplicação dos trabalhos produzidos no interior da história da historiografia, os quais teriam possibilitado um afastamento ainda maior entre o sujeito do conhecimento e os passados investigados, e isso porque ao (precisar) percorrer essas múltiplas interpretações, o historiador, ou bem não teria tempo suficiente para uma aproximação significativa em relação às suas fontes, ou mesmo já seria, necessariamente, determinado por essas leituras. No entanto, essa reflexão não deveria desestimular as pesquisas no âmbito da história, visto que essa impossibilidade de estabelecer enunciados privilegiados tornaria possível à história participar decisivamente de seu tempo, constituindo e disponibilizando, incessantemente, compreensões e juízos importantes para a orientação. 


\section{Reações}

Os textos publicados neste dossiê, bem como as discussões que tiveram lugar no interior de nosso Seminário, também possibilitam discutir a própria repercussão do giro linguístico ou, ainda, qual seriam seus desdobramentos concretos no interior da historiografia geral. Nesse sentido, é preciso matizar tais repercussões, e isso em razão das especificidades das culturas historiográficas; no entanto, sublinhamos um problema que consideramos geral e que chamamos de giro ético-político. Com efeito, independentemente de qual cultura historiográfica e de qual tradição esteja em questão (a fenomenológico-hermenêutica ou a neo-historicista), as reflexões e compreensões disponibilizadas a partir do giro linguístico apontam para a constituição de um horizonte comum no interior da teoria e da história da historiografia contemporâneas, a saber: (1) o sujeito do conhecimento não pode produzir enunciados privilegiados em relação à realidade, a despeito das teorias e métodos em questão e (2) a historiografia possui uma determinação específica, a de pensar e/ou intervir no mundo que é o seu.

Não obstante os argumentos que possamos utilizar, quer favoráveis ou contrários a esse horizonte, parece que o mundo contemporâneo, posterior ao giro linguístico, tornou-se profundamente crítico de toda e qualquer argumentação fundada na possibilidade da produção de enunciados privilegiados em relação ao real, de modo que podemos acompanhar certa consequência mais propriamente geral provocada pelo giro linguístico no interior da teoria e da história da historiografia contemporâneas, a saber, a sua fundamentação ou

328 mesmo justificativa ético-política (e, aqui, "ética" significa pensar seu mundo e "política", algo como uma intervenção mais imediata e pró-ativa). Apesar das muitas diferenças no que tange às reflexões de autores contemporâneos como Gumbrecht, François Hartog, Frank Ankersmit, Rüsen, Hayden White, Chris Lorenz, Marcelo Jasmim, Berber Bevernage, Luiz Costa Lima, Elias Palti, entre outros, a impressão que temos é a de que, justo em razão do questionamento radical e da perda do valor de convencimento da justificativa - produzir conhecimento sobre o passado - , e isso a partir do giro linguístico, a teoria e a história da historiografia contemporâneas têm no critério pensar e/ou intervir no mundo, ou seja, na pretensão ético-política, o ponto de determinação ou mesmo o motivo fundamental a partir do qual insiste (e justifica) em tematizar passados no interior do presente.

Autores como Gumbrecht estão preocupados com a possibilidade de a história da historiografia contemporânea insistir na liberação de passados a partir do que chama de "realismo impossível", e isso com o intuito de ampliar a sensibilidade humana, o que significa, mais propriamente, a possibilidade de provocar uma relação mais adequada entre a sensibilidade, a realidade sempre complexa e o aparato intelectivo (GUMBRECHT 2011; 2014). É nesse sentido, aliás, que podemos pensar o problema da Stimmung como cara à reconstituição (intensificação) de passados. François Hartog também se preocupa com o problema de um diagnóstico do mundo contemporâneo, o qual seria determinado por um "regime de historicidade" específico, o do "presentismo", de modo que a teoria e a história da historiografia podem constituir-se como âmbito ideal 
para a tematização desse tempo, tornando possível a investigação dos motivos responsáveis pelo que podemos chamar de uma relação "desequilibrada" entre o presente e determinados passados. O que está em questão aqui, para o historiador francês, é que o século XXI ainda estaria profundamente ligado ao século $X X$, especialmente a partir de uma espécie de desejo de retematização e de reparação (talvez) "excessivos" em relação a determinados acontecimentos históricos críticos e traumáticos em relação aos quais os homens, desde sua ocorrência, não teriam se posicionado de forma efetivamente "responsável". Uma reflexão possível quanto a esse problema pode ser feita a partir da questão do "patrimonialismo" (HARTOG 2006).

Rüsen sublinha que o critério de verdade próprio da "representação de continuidades" precisa ser a força de rearticulação de determinados passados, reconsiderados, no interior do presente, ou, ainda, tratar-se-ia da própria potência de orientação da narrativa historiográfica. Assim, os protocolos da ciência histórica (fundamentais) serviriam menos à produção de enunciados privilegiados e mais à constituição de um âmbito maximamente "desideologizante", ou seja, ideal para uma crítica ampla, atenta e cuidadosa, capaz de reduzir o poder de convencimento de compreensões individualizantes que advenham da política, da arte, da religião, bem como da própria teoria e da história da historiografia. Frank Ankersmit assinala que é justo a impossibilidade de produção de enunciados privilegiados em relação a passados que torna possível uma intervenção específica da teoria e da história da historiografia no tempo presente, e isso porque elas disponibilizariam uma gama múltipla e dinâmica de sugestões que podem se tornar adequadas ao próprio movimento de constituição (de diferenciação e de estabilização provisória) da "História".

Os caminhos são múltiplos, e também são ambíguas as repostas que podemos encontrar para esse lugar da historiografia como atividade intelectual rigorosa em nosso tempo. Como destacam autores como Heidegger e Derrida, o discurso histórico moderno tende a congelar a representação do passado como algo simultaneamente instável e disponível. Se cada presente produz sua própria história, sempre teremos cada vez mais histórias disponíveis, mas esse excesso de histórias se desfaz assim que o próprio fundamento desse presente demiurgo autocentrado se desmancha no interior de suas concentrações. O presente não tem como fundamentar o passado e ao mesmo tempo querer fundar-se nesse passado inventado. Esse círculo vicioso do modernismo, tantas vezes denunciado, ajuda a entender a ambivalência de um mundo que ao mesmo tempo está carente de passado e repleto de passado. As representações do passado que chegam até nós não só pela historiografia, mas também por meio de diversas fontes e atores sociais (o que podemos chamar de "cultura histórica" a partir de Rüsen), não são capazes de orientar e abrir o futuro e também pouco ajudam no descongelamento das macrorrepresentações modernas. As grandes produções televisivas, por exemplo, são cada vez mais cuidadosas nos aspectos materiais da representação, nos figurinos, nos cenários, até nas formas sociais de reprodução da vida em Roma, na Itália renascentista ou na época vitoriana, mas os modelos interpretativos, as narrativas implícitas ou explícitas permanecem 
fundamentalmente modernas (bem delimitadas e hegemônicas), o que, salvo exceções, pode também ser afirmado para boa parte da historiografia científica produzida. A história do progresso liberal, definida por Hayden White como essencialmente cômico-conciliatória, ainda é, basicamente, o ar que respiramos nas representações públicas da história.

Enfim, procuramos apresentar algumas reflexões que se tornaram possíveis a partir de nosso Seminário e dos textos que ora publicamos, a saber: (1) algumas condições de possibilidade de instauração e intensificação do giro linguístico a partir dos séculos XVIII e XIX; (2) duas tradições distintas que constituíram esse movimento epistemológico; e (3) o que consideramos ser um desdobramento geral do giro linguístico no interior da teoria e da história da historiografia contemporâneas, a saber, o esgotamento da autonomia e do poder de persuasão da justificativa de que a historiografia produz conhecimentos privilegiados sobre os passados e de que, logo, tematizamos o passado para isto, para conhecê-lo (mesmo que apenas parcialmente), e mesmo para nos orientarmos, já que podemos conhecê-lo. O que se desdobra, por conseguinte, a partir do que chamamos de giro ético-político próprio ao mundo contemporâneo, é que a teoria e a história da historiografia estão se constituindo como âmbitos ideias para o pensamento e/ou para a intervenção em seu tempo. E isso não porque podemos conhecer o passado e, então, pensar e intervir em nosso mundo, mas sim porque a sua tematização, em qualquer âmbito da cultura histórica, inclusive no interior da disciplina história, terá, sempre, o poder (necessário) de

3.30 mobilizar os homens. Ao fim, se trata de uma necessidade fundada, ou bem no "fascínio", ou bem na "consciência histórica", mas sempre de uma necessidade.

\section{Referências bibliográficas}

ANKERSMIT, Frank. A escrita da História: a natureza da representação histórica. Londrina: Eduel, 2012.

. Historiografia e pós-modernismo. Topoi: revista de história, v. 2, p. 113-135, 2001.

ARAUJO, Valdei Lopes de. A aula como desafio à experiência da história. In: GONÇALVES, Márcia de Almeida et al. (orgs.). Qual o valor da história hoje? Rio de Janeiro: FGV, 2012.

. História da historiografia como analítica da historicidade. História da Historiografia, v. 12, p. 34-44, 2013.

Formas de ler e aprender com a História no Brasil joanino. Acervo, v. 22, p. 85-98, 2009.

- Observando a observação: sobre a descoberta do clima histórico e a emergência do cronótopo historicista, c. 1820. In: CARVALHO, José Murilo; CAMPOS, Adriana Pereira (orgs.). Perspectivas da cidadania no Brasil Império. Rio de Janeiro: Civilização Brasileira, 2011, p. 281304. v.1. 
. Para além da auto-consciência moderna: a historiografia de Hans Ulrich Gumbrecht. Varia História, v. 22, p. 314-328, $2006 a$.

- Sobre o lugar da história da historiografia como disciplina autônoma.

Locus, Juiz de Fora, v. 12, p. 79-94, 2006b.

BENJAMIN, Walter. Sobre o conceito de história. In: LÖWY, Michel. Aviso de incêndio: uma leitura das teses "Sobre o conceito de Historia". São Paulo: Boitempo, 2005.

BEVERNAGE, Berber. History, Memory and State-Sponsored Violence: Time and Justice. Routledge, 2012. (Edição eletrônica).

CASANOVA, Marco Antonio. Compreender Heidegger. 4a edição. Petrópolis: Vozes, 2013.

FOUCAULT, Michel. As palavras e as coisas: uma arqueologia das ciências humanas. São Paulo: Martins Fontes, 1999.

GUMBRECHT, Hans Ulrich. Atmosfera, ambiência, "Stimmung": sobre um potencial oculto na literatura. Rio de Janeiro: Constraponto/PUC-RJ, 2014.

. Depois de "Depois de aprender com a história", o que fazer com o passado agora? In: NICOLAZZI, Fernando; MOLLO, Helena Miranda; ARAUJO, Valdei Lopes de (orgs.). Aprender com a história? O passado e o futuro de uma questão. Rio de Janeiro: Editora FGV, 2011.

- Em 1926: vivendo no limite do tempo. Rio de Janeiro/São Paulo: Editora Record, 1999.

Modernização dos Sentidos. São Paulo: Editora 34, 1998.

HARTOG, François. Régimes d’historicité: présentisme et expériences du temps. Paris: Éditions du Seuil, 2003.

. Tempo e Patrimônio. Varia História, vol. 22, n 36, p. 261-273, jul/ dez, 2006.

HeIDEGger, Martin. Ser e Tempo. Petrópolis: Vozes; Bragança Paulista: Editora Universitária São Francisco, 2008.

. Sein und Zeit. Tübingen: Max Niemeyer Verlag, 2006.

KOSELLECK, Reinhart. Futuro Passado: contribuição à semântica dos tempos históricos. Rio de Janeiro: Contraponto/PUC-Rio, 2006.

LYNCH, Christian Edward Cyril. Monarquia sem despotismo e liberdade sem anarquia: o pensamento político do Marquês de Caravelas. Belo Horizonte: Editora UFMG, 2014.

RANGEL, Marcelo de Mello. Justiça e história em Derrida e Benjamin. Sapere Aude: revista de filosofia, v. 4, p. 347-359, 2013.

O problema da ciência histórica em Friedrich Nietzsche e Walter Benjamin. Revista Urutágua, v. 23, p. 78-84, 2011. 
. Romantismo, Sattelzeit, melancolia e "clima histórico" (Stimmung). Expedições: teoria da história e historiografia, v. 5, n. 1, 2014. - Sobre a utilidade e desvantagem da ciência histórica, segundo Nietzsche e Gumbrecht. Dimensões, vol. 24, p. 208-241, 2010.

RANGEL, Marcelo de Mello; RODRIGUES, Thamara de Oliveira. História e Modernidade em Hans Ulrich Gumbrecht. Revista Redescrições, ano 3, n. 4, p. 63-71, 2012.

RÜSEN, Jörn. Razão Histórica. Teoria da história: os fundamentos da ciência histórica. Brasília: Editora Universidade de Brasília, 2001.

WHITE, Hayden. El Texto histórico como artefacto literario. Barcelona: Ediciones Paidós. I.C.E. de la Universidad Autónoma de Barcelona, 2003. 